\title{
Hydrogen as Fuel in Automobiles
}

\author{
Mahammed Nazim Shaik \\ R.Y.M Engineering College, Bellary.-04, India
}

\begin{abstract}
As we all know pollution is increasing day by day in our Daily life. In earlier days we were used to measure, which city is most polluted but unfortunately in now a days we are ranking the city which is least polluted. In New Delhi (Capital of India) during 1971 there were only 2.17 lacks of vehicles using Petrol or Diesel, by 2011 the number of vehicles were increased to 6000 lacks. Since it's possible to control the number of vehicles but it will not be suitable. Instead we can use Hydrogen as a fuel in our automobiles by making some engine modifications, thereby reducing the pollution.
\end{abstract}

Keywords: Hydrogen, Fuel, Automobiles, Hydrogen production\& Transportation, Engine modifications

\section{Introduction}

Hydrogen as alternate fuel is more beneficiary since its combustion releases the water in the form of steam as a byproduct.

As we know the oil deposits are getting depleted day by day so its better to shift to some alternate fuel which is Hydrogen.

Hydrogen being highly reactive it never occurs in Free State. The main source of hydrogen is Water i.e; (Two molecules of Hydrogen and one molecule of oxygen) which abundantly available to us and hence to no such chance getting scarce in source. There is another befit of hydrogen production from water that is the oxygen is liberated at another electrode which can be used in hospitals.

The combustion of hydrogen with oxygen produces water as its only product: $\quad 2 \mathrm{H} 2+\mathrm{O} 2 \rightarrow 2 \mathrm{H} 2 \mathrm{O}$

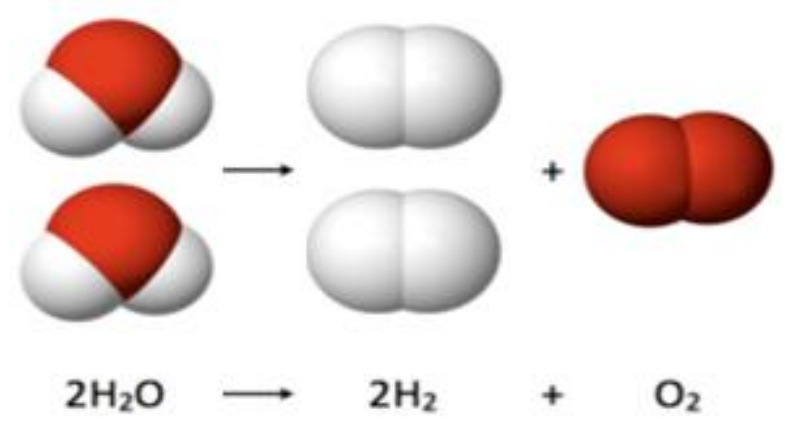

Hydrogen as a fuel has some significant properties like;

- Hydrogen has the highest energy content per unit mass and hence it can be directly used as a fuel in aircrafts.

- The heating value of liquid hydrogen is $8400 \mathrm{MJ} /$ cubic meter as compared to $32000 \mathrm{MJ} /$ cubic meter of aviation of gasoline/petrol.

- Hydrogen has a density of about $1 / 4^{\text {th }}$ of that of air \& $1 / 9^{\text {th }}$ that of natural gas.

- A liquid hydrogen has a specific gravity of 0.07 which is comparatively $1 / 10^{\text {th }}$ that of gasoline/petrol.

\section{Hydrogen Fuel Enhancement}

Hydrogen fuel enhancement is the process of using a mixture of hydrogen and conventional hydrocarbon fuel in an internal combustion engine, typically in a car or truck, in an attempt to improve fuel economy, power output, emissions, or a combination thereof. Methods include hydrogen produced through electrolysis, storing hydrogen on the vehicle as a second fuel, or reforming conventional fuel into hydrogen with a catalyst.

There has been a great deal of research into fuel mixtures, such as gasoline and nitrous oxide injection. Mixtures of hydrogen and hydrocarbons are no exception. These sources say that contamination from exhaust gases has been reduced in all cases, and they suggest that a small efficiency increase is sometimes possible.

Many of these sources also suggest that modifications to the engine's air-fuel ratio, ignition timing, emissions control systems, electronic control systems. Due to the inherent complexity of these subsystems, a necessity of modern engine design and emissions standards, such claims made by proponents of hydrogen fuel enhancement are difficult to substantiate and always disputed.

\section{Hydrogen Internal Combustion Engine Vehicle}

A hydrogen internal combustion engine vehicle (HICEV) is a type of hydrogen vehicle using an internal combustion engine.[1] Hydrogen internal combustion engine vehicles are different from hydrogen fuel cell vehicles (which use electrochemical conversion of hydrogen rather than combustion); the hydrogen internal combustion engine is simply a modified version of the traditional gasolinepowered internal combustion engine.

Some of the companies trying to manufacture HICEV are as follows;

- Mazda has developed Wankel engines that burn hydrogen.

- BMW tested a luxury car named the BMW Hydrogen 7, powered by hydrogen.

- Alset $\mathrm{GmbH}$ developed hybrid hydrogen systems that allows vehicle to use petrol and hydrogen fuels individually or at the same time with an internal combustion engine.

Thus when the revolution of hydrogen vehicles start then comes the problem in production, transpiration, and Storage of Hydrogen. 


\section{International Journal of Science and Research (IJSR) \\ ISSN (Online): 2319-7064}

Index Copernicus Value (2015): 78.96 | Impact Factor (2015): 6.391

Even this problem can be eradicated by erecting the hydrogen production stations just like thermal power plants and when it comes to transportation underground pipeline must be established. The above plan must be started from metro cities later slowly expanding it to other cities.

\section{Hydrogen Production}

The simplest and convenient method of hydrogen production is the electrolysis of water which involves the splitting up of water in to Hydrogen and oxygen by passing direct electric current.

There are some other methods like;

- Steam reformation.

- Coal gasification

- Methane gas reformation.

- Biological production of hydrogen.

- Photo electrolysis.

\section{References}

[1] Non- conventional Energy Source by Author G.D Rai.

[2] Non-conventional Energy Source by Dr.R.K Sighal.

[3] Wikipedia the great Encyclopaedia. 